Proceedings of the 2011 Winter Simulation Conference

S. Jain, R. R. Creasey, J. Himmelspach, K. P. White, and M. Fu, eds.

\title{
ENERGY EFFICIENCY ANALYSIS FOR A CASTING PRODUCTION SYSTEM
}

\author{
Jonatan Berglund \\ John Michaloski \\ Swee Leong \\ Guodong Shao \\ Frank Riddick
}
GM Global Research \& Development
Warren, MI 48090, USA

\author{
Jorge Arinez \\ Stephan Biller
}

\author{
National Institute of Standards and Technology \\ Gaithersburg, MD 20899, USA
}

\begin{abstract}
A growing number of manufacturing industries are initiating efforts to address sustainability issues. A study by the National Association of Manufacturers indicated that the manufacturing sector currently accounts for over a third of all energy consumed in the United States. There are many areas and opportunities to reduce energy costs and pollution emissions within a manufacturing facility. One way to achieve an energy efficient manufacturing system is to measure and evaluate the combined impact of process energy from manufacturing operations, their resources (e.g., plant floor equipment), and facility energy from building services (e.g., ventilation, lighting). In this paper, issues associated with integrating production system, process energy, and facility energy to improve manufacturing sustainability are explored. A modeling and simulation case study of analyzing energy consumption in a precision casting operation is discussed.
\end{abstract}

\section{INTRODUCTION}

A driving force behind sustainable manufacturing is cleaner and more efficient production. The U.S. Department of Commerce defines sustainable manufacturing as "the creation of manufactured products that use processes that are non-polluting, conserve energy and natural resources, and are economically sound and safe for employees, communities, and consumers." Sustainable manufacturing covers a wide range of concepts, including profit, environmental impact, product life cycle, user experience, recyclability, etc., but currently energy consumption commands great attention since it improves both the bottom line and the environment. Energy management is challenging for manufacturing due to the difficulty that arises from the diversity of energy use - there are thousands of processes, each having unique energy consumption characteristics as well as different production requirements based on the product, product quality, environmental compliance, and other business factors (U.S. Congress, Office of Technology Assessment 1993).

The motivation for striving for more energy efficient manufacturing is well-documented. It is estimated that manufacturing in the United States uses one-third of all the energy consumed (U.S. Department of Energy 2004). Considering that buildings constitute about $39 \%$ of all energy use, a substantial portion of manufacturing energy use is attributable to the building facility apart from any manufacturing activities. Thus, to achieve sustainable manufacturing, one must consider the energy consumption impacts of both production and the associated factory. Given these energy numbers, the smarter integration of production system, process energy, and facility energy data presents a clear-cut opportunity to improve manufacturing sustainability (Arinez and Biller 2009).

Integrating the knowledge of the process and facility is critical for achieving more sustainable manufacturing operations. Unfortunately, production and facility energy relationships are modeled in a suboptimal way. Part of the problem can be attributed to the functionality schism between energy management sys- 
tems (EMS), which handle energy-related activities within building services, and manufacturing execution systems (MES), which handle production activities. In effect, MES and EMS are "silo" operations, that is, isolated subsystems from each other. However, facility energy consumption, though not directly linked to production system performance, can nevertheless be indirectly correlated to meet the requirements of sustainable manufacturing.

To understand the complicated relationships involved in modeling the energy efficiency, simulation modeling of production and facility energy can be highly beneficial as it is well-suited to handle the complexity of large scale interaction of building, machines, and processes. Simulation can be effectively used to model real or proposed production and evaluate concepts, identify problem areas, and quantify and optimize system performance. Simulation is especially popular when the intricacy of real world makes analytical closed-form solutions difficult. Simulation that models a system as a chronological sequence of discrete events is known as Discrete Event Simulation (DES). DES is useful for modeling and analysis of manufacturing systems, such as machinery operation, shop workflow and scheduling, and production lines.

In order to simulate and evaluate sustainability of manufacturing operations, a consolidated model of the production must be developed. The purpose of this paper is to understand the significant production energy consumption drivers and to build a DES model that incorporates process, process energy, and facility knowledge. Consolidating the large number of interrelated systems used to hold sustainability knowledge in a modern manufacturing plant complicates the modeling task. Our analysis will attempt to synthesize the "digital, virtual, and real" knowledge viewpoints into one coherent model for sustainability analysis purposes (Lanz and Tuokko 2009). First, we will characterize the width of sustainable production knowledge found in the manufacturing and facility systems; and then use the Core Manufacturing Simulation Data (CMSD) specification (SISO 2010) as the common neutral representation in which to collate the sustainable production knowledge. Next, we develop a DES model of a precision sand casting operation as a case study for the analysis.

This paper studies the issues related to DES modeling of production and facility energy consumption. In Section 2 the production/facility "silo" manufacturing architecture is further examined and a formal characterization consisting of the various elements that contribute to the sustainability knowledge is presented. In Section 3, a case study of an automotive precision sand casting operation using DES is presented. The paper is concluded by a discussion on the results and a presentation of the future direction of this research work.

\section{MANUFACTURING ENERGY ANALYSIS}

Today, most manufacturing energy management is done by separate plant information systems and is not well-linked to production data. Though possible, it is quite costly, especially in older facilities, to perform extensive energy data collection at the equipment level. Increasingly, energy efficiency is drawing the attention of industry. Several industrial network groups are implementing energy awareness into their specifications (ODVA 2011, PROFINET 2011). Several strong use-case scenarios exist for network-enabled energy management, including optimized production processes leading to energy savings during short, long, and unplanned interruptions.

In general, incorporating energy efficient measures into manufacturing processes can be achieved without adverse effect (Rachuri et al. 2009). Significant sustainable analysis covering the spectrum of industrial processes has already been conducted by industry, government, and academia. Further, a great deal of effort has focused on the study of industrial processes (Gutowski et al. 2007, Jiang et al. 2008) or energy consumption of individual machines (Dietmair and Verl 2009, Narita et al. 2008, Dahmus and Gutowski 2004). Research into building sustainability is common, with analysis into the relationships between building architecture, energy conservation, construction materials, and climate being primary areas of study (Kibert 2007, U.S. Green Building Council 2005, Issa et al. 2009). However, analysis of process and facility knowledge to yield sustainable benefits is evident, but is only now being explored. As a prerequisite, an integrated approach to handling production and facility energy consumption is required, 
Berglund, Michaloski, Arinez, Leong, Shao, Riddick, and Biller

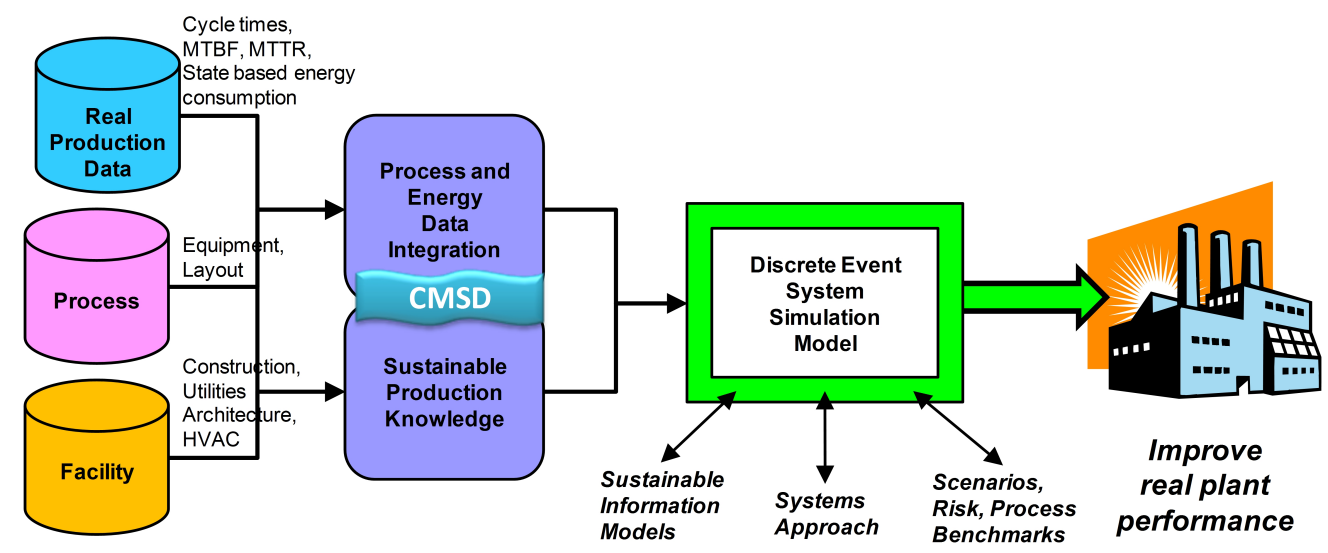

Figure 1: Sustainable Production Integration.

as many production facility conservation measures cannot be undertaken without a complete understanding of the symbiotic but loosely correlated relationship of the two manufacturing elements.

The long-term strategic goal of our effort is to develop a systems approach to integration of production and facility system and energy data for sustainable manufacturing (Arinez et al. 2010). Figure 1 illustrates the concepts in integrating production and facility data for sustainable manufacturing. Real production data, process energy, and facility energy data are all required to be collated and synthesized into process/energy data, as well as sustainable production knowledge. Real production data can be used to describe processes using statistical characterization. Process and energy data integration relates to the amount of energy required during production. This encompasses not only the amount of energy required to run a machine, but would also include facility functions such as lighting, compressed air, and air quality control, for example, correlating Heating, Ventilation, and Air Conditioning (HVAC) to production heat and emissions. Sustainable Production Knowledge includes more static information such as machine size and location on the plant floor, as well as its spatial relationship to HVAC air supply.

The development of the DES model is a large undertaking, but can be handled in phases to incorporate increasingly detailed parameterization. Given the production and facility data, the factory is modeled in DES so that potential scenarios can be run to project different operational outcomes. Assuming a robust model, DES is aptly suited as a way to understand energy consumption as it relates to process and facility control, since a DES model can run benchmark data to determine optimizations, savings, and drawbacks, as well as mitigate risks, and help avoid potential crisis points. For example, benchmarks could be used to understand the implications of energy usage during production stoppages, the effect of changing production schedules, or what can be done to lower the risk associated with rising energy costs or energy shortages.

\subsection{Modeling Process Energy}

Evaluating energy performance of a production system requires accurate information on how, when, and where process energy is being used. We will attempt to formalize the collecting and tracking of process energy data. Process energy data is based on integrated measurements over time to determine power consumption, but may include peaks, spikes, and other cost-sensitive parameters that are out of scope for this paper. For this analysis, the key energy parameter is not only power consumed, but also correlating time-based energy readings to the underlying process state, for example, the amount of energy being consumed while processing, versus the amount of energy being consumed when the resource is down.

The sustainable machining energy models found in the literature implicitly specify a state-based methodology, establishing an "Idle" or "Ready" machine energy baseline for power consumption, and a "Busy" or processing state as well. We sketch a state-based formalization of the resource energy consumption based on enumerating the states required for the modeling. 


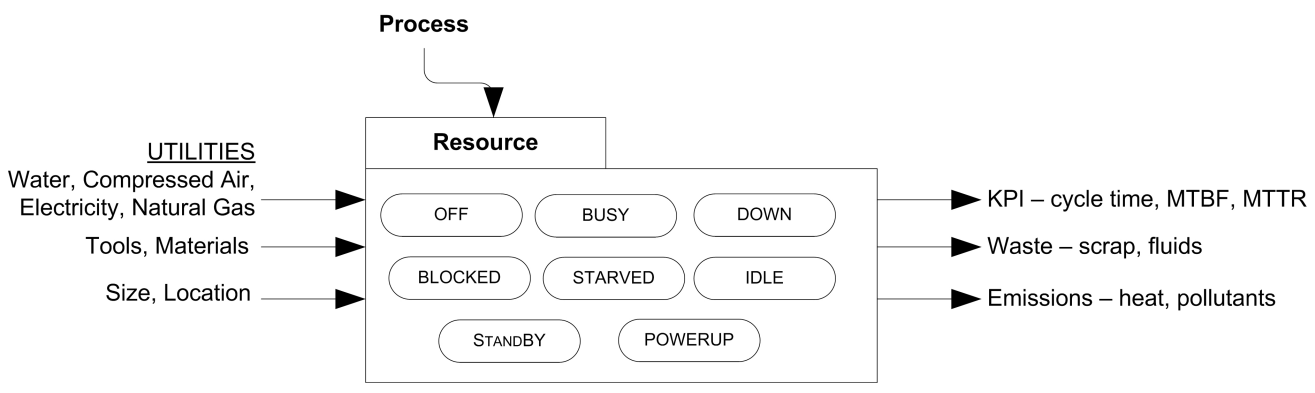

Figure 2: Modeling Resource Energy.

In Figure 2, the basic state machine formalism is given as: OFF, BUSY, DOWN, BLOCKED/STARVED, IDLE, STANDBY, and POWERUP, whose states are described by:

- $\mathbf{O F F}$ - the equipment being powered off.

- BUSY - the equipment power consumption where the manufacturing process is in an active state.

- DOWN - the equipment power consumption in an alarm or fault state.

- BLOCKED/STARVED - the state where the manufacturing process is inactive due to upstream/downstream processing issues.

- IDLE - the equipment power consumption where the process is an inactive state.

- STANDBY - a reduced power consumption state, while the manufacturing process waits.

- POWERUP - the equipment power consumption while warming up.

STANDBY describes an equipment state that would be greatly beneficial, but is rarely found in manufacturing equipment. As mentioned earlier, the utility of this capability is well-understood and network solutions are emerging. STANDBY involves powering the equipment into a sleep mode that saves energy by utilizing the least amount of power required. Since it is common for equipment to be temperature sensitive and require a "warm-up" period, mere inactivity would not be sufficient for going into STANDBY state, as typically done by a computer after 15 minutes of inactivity. Instead, higher-level manufacturing control with total process understanding would need to assess the cause, extent, and duration of any process inactivity and then make control decisions based on a more complete picture. Implicit in this STANDBY state is the need to account for POWERUP activity in order to resume production with the equipment.

Using a state model, resource energy consumption can be modeled as a cost-function, which maps machine energy usage to particular states. Factory equipment such as fans, machinery, conveyors, or lighting can all be modeled by state machines. A state model is particularly useful because it is equally applicable for either production or for facility equipment. The only difference is that for facility equipment, the starved or blocked states would never arise.

Modeling each state element of the resource energy as a linear cost function will yield the total resource energy cost. Since each resource can be used for any number of $P$ processes, the state function must track each process, and the time in each state to derive the associated cost function. This leads to the following cost function $C(R \otimes p)$ for a resource $R$ and a process $p$ over the range of processes $P$ :

$$
\begin{aligned}
C(R \otimes p)= & C_{\text {OFF }}\left(t_{\text {off }}^{j}\right)+C_{\text {IDLE }}\left(t_{\text {idle }}^{j}\right)+C_{\text {DOWN }}\left(t_{\text {down }}^{j}\right)+C_{B U S Y}\left(t_{\text {busy }}^{j}\right) \\
& +C_{\text {STARVED }}\left(t_{\text {starved }}^{j}\right)+C_{\text {BLOCKED }}\left(t_{\text {blocked }}^{j}\right)+C_{\text {STANDBY }}\left(t_{\text {standby }}^{j}\right)+C_{\text {POWERUP }}\left(t_{\text {powerup }}^{j}\right)
\end{aligned}
$$

where $j=1, \ldots, P$ and $C_{S}\left(t_{S}^{j}\right)=$ time spent in state $S$

such that $C_{O F F}\left(t^{j}\right) \approx 0 \quad \forall j=1, \ldots, P$ 
Collecting process energy data is best achieved by transforming the timed data into state-based power consumption. This assumes the energy data is of fine enough granularity, so the transformation can be programmatically determined by correlating the power consumed during a process state and integrating over time. Should the energy data be coarse readings, such as daily or shift summaries, numerical algorithms will be required to perform statistical and selective modeling techniques that can roughly estimate the power consumed for the process states.

\subsection{Characterizing Production/Facility Use}

A large number of modeling factors are critical in effectively developing a sustainability model for a manufacturing system. Manufacturing systems involve a number of interrelated elements, including but not limited to: equipment strategy, number of product options, material handling systems, system size, process flow configuration, processing time of the operations, system and workstation capacity, and resource utilization. The model must be combined with other constraints such as unpredictable machine breakdowns, varying operational requirements, schedule variation, and different production demands.

A top level characterization of the primary sustainable production information leads to the following formalization:

$$
S_{K}=B_{A}+B_{C}+B_{H V A C^{E}}+B_{U}+R_{P}+R_{H V A C^{L}}+R_{U}+R_{E}+R_{E M}+K P I_{R \otimes P}+\text { Part }_{E}
$$

Where

$$
\begin{aligned}
S_{K}= & \text { Sustainable Knowledge } \\
B_{A}= & \text { building architecture, including rooms, sizes, windows, etc. } \\
B_{C}= & \text { building construction materials for walls, ceiling, insulation } \\
B_{H V A C}= & \text { building energy required to run the heating, ventilation and air condition } \\
& \text { capabilities. } \\
B_{U}= & \text { building utility energy monitoring, including lighting. } \\
R_{P}= & \text { profile of resource, including location of the resource, size dimensions, } \\
& \text { orientation } \\
R_{H V A C}= & \text { Layout relationship to the supply and return air flow related to building } \\
& \text { heating, ventilation and air condition } \\
R_{U}= & \text { baseline resource utility consumption, including electricity, natural gas, } \\
& \text { compressed air, hydraulics, water } \\
R_{E}= & \text { process and state-based resource utility consumption, including electricity, } \\
& \text { natural gas, compressed air, hydraulics, water } \\
R_{E M}= & \text { the heat emissions generated by the resource. } \\
K P I_{R \otimes P}= & \text { Key performance indicators (KPI) such as cycle time, mean time be- } \\
& \text { tween failures (MTBF), mean time to failure (MTTF), mean time to repair } \\
& \text { (MTTR). Depending on the sophistication of the data collection, statistical } \\
& \text { characterization can be done in the best case per process on a resource, } \\
& \text { and in the worst case per resource or process individually. }
\end{aligned}
$$

Of note, Part $_{E}$ can be used to capture additive production energy. For example, the additive energy from injecting molten metal into production can represent any continuous processes that may have outsourced 
molten metal delivered and added to production via holding furnaces. The production system will most likely maintain an operating molten temperature approximately equivalent to the dispensed molten metal. The outsourced molten metal adds energy to the system that can lead to incorrect energy cost analysis and breaking down the interaction between HVAC and molten heat emission could be difficult. Instead, energy balancing may be used to understand energy use based on the amount of molten metal and the natural gas or electricity used to maintain the molten temperature and then the amount of molten metal yield and scrapped within production, given as:

$$
E=E_{\text {outsource }}(M)-E_{\text {produced }}(M)-E_{\text {scrapped }}(M)+E_{\text {utilities }}
$$

where $E$ is measured in normalized energy units, such as Joules.

Above, $B_{U}$ and $R_{E}$ share some knowledge overlap that must be resolved by carefully analyzing the data available. Facility energy and production management systems could both be able to read the electrical usage of the equipment. It would be preferable if the resource energy value, $R_{E}$, could be read directly from production equipment. Unfortunately, equipment process energy data is frequently not available unless a special effort has been made to acquire the energy data from the machine controller or via power monitoring sensors. Assuming the facility EMS can monitor and collect production energy, the problem of data granularity level can occur (e.g., data collected at the substation meter level as opposed to equipment resource level). Further, even when $B_{U}$ energy data is available, it can be difficult to use, as it is often located in unconnected and incompatible data collection subsystems (Arinez et al. 2010). Given separate systems and databases, this greatly complicates the sharing of sustainable production knowledge.

\subsection{Sustainable Knowledge Fusion}

For larger scale production, the integration of sustainability knowledge from a variety of sources is a challenge. Even a medium sized production line could contain thousands of devices and tools, both discrete and continuous operations, building and layout parameters, as well as HVAC equipment. Integrating their associated data can be quite a challenge. Consequently, a major obstacle to production/facility energy analysis is the necessary and complex integration of information from different applications (CAD drawings, spreadsheets, and databases) with different representations to model the sustainable knowledge. Because of this breadth and disparity of information and sources, a move towards a common repository format with one unifying and neutral information model would be of great benefit to facilitate sustainability modeling and analysis.

Currently, it can be quite difficult to extract knowledge into a common knowledge format. Digital CAD drawings are used for the facilities and plant layout, process plans are contained in data bases, and workflow data in spreadsheets, so that various pieces of production knowledge may be distributed throughout the enterprise. Often, storage of the production knowledge is tailored for human comprehension, i.e., spreadsheets, that are not as conducive for digital sharing.

There are several useful domain-specific standard representations that can make the integration easier. The Industry Foundation Classes (IFC) is the information model developed by the International Alliance for Interoperability (IAI) to facilitate interoperability in the building industry. IFC provides a domain-specific (building terminology and concepts) to represent the building. The IEC (International Electrotechnical Commission) 61970-301 Common Information Model (CIM) standard (International Electrotechnical Commission 2003) provides a standard representation and data exchange format for electric power transmission and distribution technology. Although these standards exist and would make sustainability knowledge integration easier, technology that implements the standards is not always readily available.

Assuming enough sustainability knowledge is available, a neutral format to represent this data is desirable. Core Manufacturing Simulation Data (CMSD) is a standard specification that would allow the translation from numerous related domains into a manufacturing domain-specific representation suitable for sustainable analysis. The CMSD specification focuses on core modeling concepts shared by all manufacturers 
Berglund, Michaloski, Arinez, Leong, Shao, Riddick, and Biller

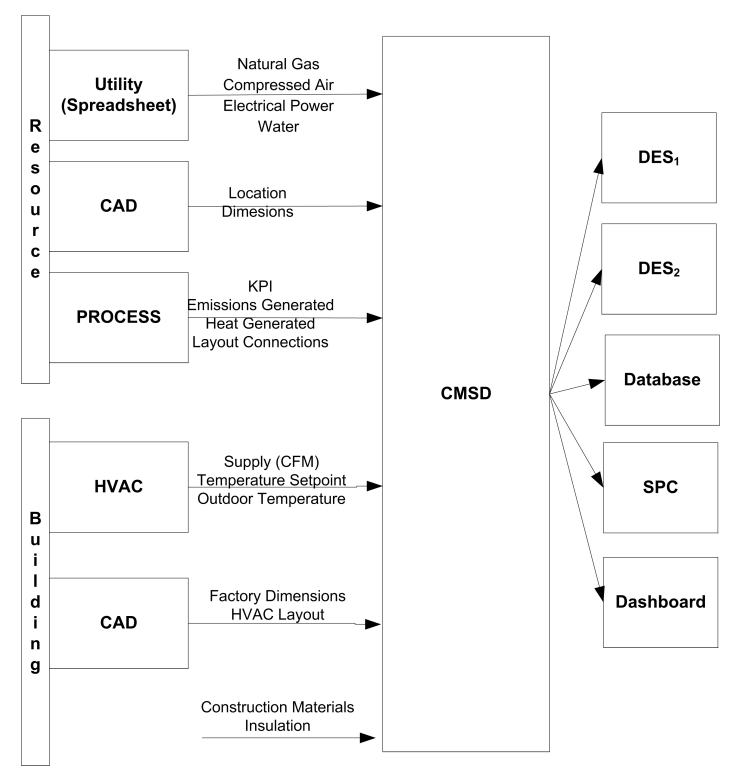

Figure 3: Knowledge Fusion into CMSD Representation.

and provides a generic property structure to adapt to various specialized functional requirements. The format of CMSD data is CMSD eXtensible Modeling Language (XML), which adheres to the CMSD XML Schemas (XSD). CMSD XML provides a standard format that contains the basic data required to represent the sustainable information while simultaneously allowing additional, detailed, application-specific data to be contained without invalidating the format. Even if XML currently is not supported by all applications, it provides a widely accepted format that numerous tools can translate into appropriate internal proprietary formats. Figure 3 shows the strategy of using CMSD to convert production knowledge and process data into a common repository with a neutral representation so that it can be easily transformed into other tools, for example, DES, or database, or Statistical Process Control (SPC).

\section{CASE STUDY}

A case study to investigate the issues involving production/facility analysis was done for a precision sand casting production facility that produces aluminum engine blocks. Metal casting is an energy-intensive process; in fact, it is one of the most energy-intensive industries. As such, it is a prime candidate for energy analysis. The precision casting operation uses 23225 square meters ( 250000 square feet) of a larger facility to make polyurethane cold box sand cores that are assembled into 317.5 kilogram (700 pounds) molds. There are three mold, casting, and finishing lines, with over one thousand pieces of equipment as part of the manufacturing process.

Figure 4 shows a high-level overview of the precision casting process. The molten aluminum process is responsible for melting the aluminum, refining the melt, and adjusting the molten chemistry. Once molten, the aluminum is degassed, leveled, and laundered to remove deleterious gases before being tapped to flow into cores. Cores are made of sand that is poured into molding machines to create the contours of the casting, pressed, and heated to bind the sand. Since the sand casting process is an expendable mold metal casting process, the core process builds a new sand core for each casting. Overall, core parts are molded from sand and binding elements, assembled into the engine block core, and then dried before casting. The casting and finishing process is where the molten aluminum flows into the sand cast core, after which, the casting is cooled and then casting sand is removed from around the now solidified aluminum engine block by shakeout, trim, and degating operations. 
Berglund, Michaloski, Arinez, Leong, Shao, Riddick, and Biller

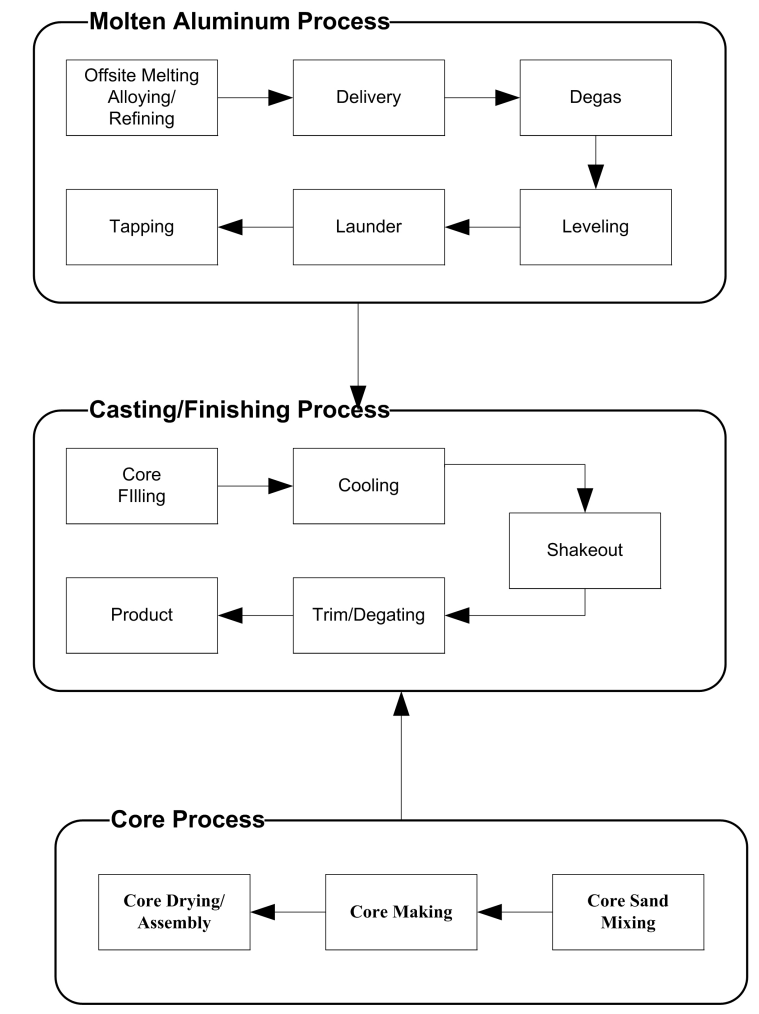

Figure 4: Precision Casting Overview.

\subsection{DES Model}

A DES model was developed that focused on the precision casting stage where the molten aluminum and the sand core packages meet and the pouring operation occurs. Figure 5 shows the model of these casting operations as developed using a commercial DES software package. The DES effort involved programming the equipment characterization, equipment arrangement, facility layout, and the process flow in a 3-D format. The equipment included pick-and-place robots, conveyors, lifts, pumps, and HVAC duct work.

The goal was to correlate production activity with the process/facility energy consumption. Cost functions for resource energy were based on resource and process properties (Cycle Time, MTTF, MTTR) collated with production schedule (demand and order levels) as well as physical layout (positioning of resources, length and speed of conveyors etc.). The DES software was utilized to log the share of total time spent in each state for all resources. The precision casting operation had energy data, but it was of the wrong granularity (at the cell or higher level) so that other means were required to estimate and understand energy consumption. For utility consuming entities such as HVAC, the molten aluminum transport and heating system, and lighting, energy consumption was estimated by differentiating between day and night energy consumption. This was possible since the precision casting operation runs one shift per day, but must maintain the aluminum in a molten state overnight and weekends. The utilities were monitored in a similar fashion to the resource consumption such that the total utility consumption was allocated to the finished engine block casts.

The major benefit of developing the DES model is to assist in the manufacturing decision-making process. DES can be used to assess the overall manufacturing system to evaluate concepts, identify problem areas, and quantify or optimize system performance. Given the DES model of the casting operation, the following outputs were calculated: 


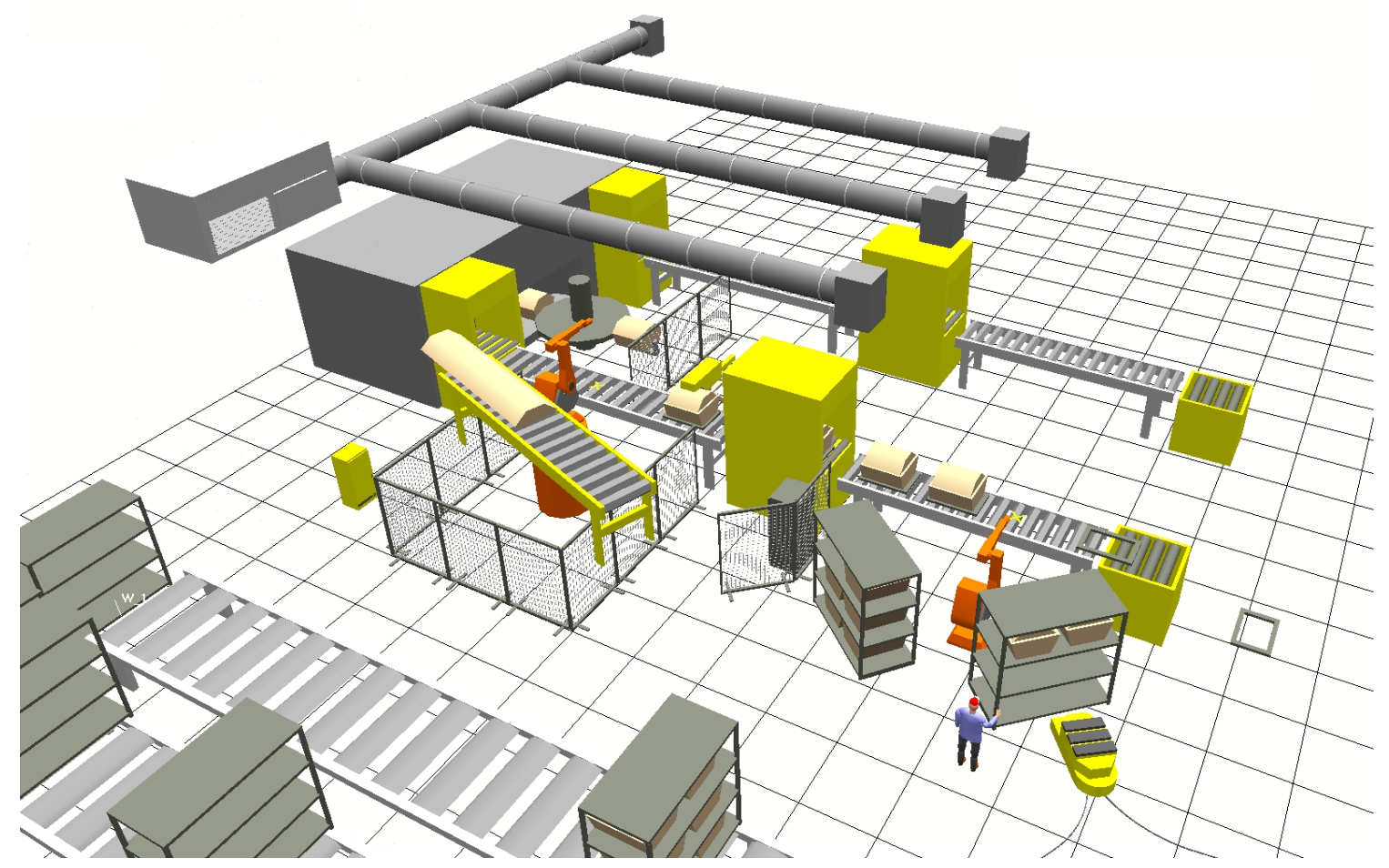

Figure 5: DES Screenshot of Casting Operation.

- Estimated electricity and natural gas consumption per part. The values captured variations in production activities and included HVAC emissions.

- Machine utilization and bottleneck analysis.

- Throughput and lead time.

- Possible strategies for combined reduction of energy consumption and productivity improvement.

Various "what-if" scenarios were also created to evaluate production system, process energy, and facility energy performance, that includes:

- Scaling back resource usage by periodically shutting down parts of the system.

- Evaluating different energy sources, such as moving completely to natural gas or electricity.

- Evaluating the potential best case environmental performance of the system and comparing it to the current performance. Factors to vary are number of shifts and number of resources in use, etc.

The case study results indicate on what is and what can be achieved. It is important to recognize that the calculated environmental and emission values are potential, rather than absolute, which is the case in most environmental assessment studies. However, they are still valuable as benchmarks on the current state and can be improved on. Also, the model accuracy can be improved continuously as data of sufficient detail level becomes available.

\section{DISCUSSION}

This paper discusses the information requirements necessary to study the sustainability aspects of a precision sand casting operation using a DES model. An energy consumption model for a plant resource and a given process was developed. Analysis for the necessary production and facility knowledge needed to build 
a sustainability model was also presented. Finally, a case study that applied the sustainability analysis methods was introduced to demonstrate the method.

The modeling concepts developed have the potential to significantly reduce manufacturing energy consumption, but still have many challenges. Collating the necessary information, filtering the raw data into statistical characterization, and resolving representation discrepancies between the EMS and MES production system is time consuming. Unlike most DES efforts, non-energy production data collection was not a major time-consuming factor (Skoogh and Johansson 2008), as raw process data was readily available and easily processed into statistical key performance indicators. However, sustainability knowledge that could simplify the process, such as HVAC air handler layout, plant layout, or equipment energy readings, was either not available or had to be estimated or in a format that could only be interpreted by manual inspection. Clearly, a common information architecture that supports the sharing and synthesis of rich domain "real, digital, and virtual" knowledge is imperative for sustainable manufacturing analysis to be cost-effective. In the future, we will be attempting to rectify the integration difficulty in collecting and fusing the broad expanse of sustainable production knowledge.

\section{ACKNOWLEDGMENTS}

The authors would like to thank Kevin Lyons, who is a group leader in the Engineering Laboratory at the National Institute of Standards and Technology, for his help in initiating this project and for providing valuable insights along the way.

\section{DISCLAIMER}

Commercial equipment and software, many of which are either registered or trademarked, are identified in order to adequately specify certain procedures. In no case does such identification imply recommendation or endorsement by the National Institute of Standards and Technology or General Motors, nor does it imply that the materials or equipment identified are necessarily the best available for the purpose.

\section{REFERENCES}

Arinez, J., and S. Biller. 2009. "Innovations in Energy Measurement and Control for Manufacturing Systems". In NIST National Workshop on Challenges to Innovation in Advanced Manufacturing: Industry Drivers and $R \& D$ Needs. Gaithersburg, MD.

Arinez, J., S. Biller, K. Lyons, S. Leong, G. Shao, B. E. Lee, and J. Michaloski. 2010. "Benchmarking Production System, Process Energy, and Facility Energy Performance Using a Systems Approach". In Performance Metrics for Intelligent Systems Workshop (PerMIS 10). Baltimore, Maryland, USA: IEEE.

Dahmus, J. B., and T. G. Gutowski. 2004. "An Environmental Analysis of Machining”. In American Society of Mechanical Engineers, Manufacturing Engineering Division, MED, 643 - 652. Anaheim, California.

Dietmair, A., and A. Verl. 2009. "A Generic Energy Consumption Model for Decision Making and Energy Efficiency Optimisation in Manufacturing". International Journal of Sustainable Engineering 2:123133.

Gutowski, T., J. Dahmus, A. Thiriez, M. Branham, and A. Jones. 2007. "A Thermodynamic Characterization of Manufacturing Processes". In IEEE International Symposium on Electronics and the Environment, 137 - 142. Orlando, Florida.

International Electrotechnical Commission 2003. "IEC 61970-301 Energy Management System Application Program Interface (EMS-API) - Part 301: Common Information Model (CIM) Base”. Technical report, Geneva, Switzerland.

Issa, R. R., P. Suermann, and S. Olbina. 2009, December. "Use of Building Information Models in Simulations". In Proceedings of the 2009 Winter Simulation Conference, edited by M. D. Rossetti, R. R. Hill, B. Johansson, A. Dunkin, and R. G. Ingalls, 2664-2671. Piscataway, New Jersey: Institute of Electrical and Electronics Engineers, Inc. 
Jiang, Z., H. Zhang, and M. Xiao. 2008. "Analysis Model of Resource Consumption and Environmental Impact for Manufacturing Process". Systems Engineering - Theory \& Practice 28:132 - 137.

Kibert, C. 2007. Sustainable Construction: Green Building Design and Delivery. Wiley.

Lanz, M., and R. Tuokko. 2009. "Generic Reference Architecture for Digital, Virtual, and Real Representations of Manufacturing Systems". In Proceedings of the Indo-US Workshop on Designing Sustainable Products, Services, and Manufacturing Systems. Bangalore, India.

Narita, H., N. Desmira, and H. Fujimoto. 2008. "Environmental Burden Analysis for Machining Operation Using LCA method". In Manufacturing Systems and Technologies for the New Frontier, edited by M. Mitsuishi, K. Ueda, and F. Kimura, $65-68$.

ODVA 2011. "Optimization of Energy Usage: ODVA's Vision of Energy Optimization for the Industrial Consumer". Technical Report PUB00246, Ann Arbor, MI.

PROFINET 2011. "Common Application Profile PROFIenergy Technical Specification for PROFINET".

Rachuri, S., R. Sriram, and P. Sarkar. 2009. "Metrics, Standards and Industry Best Practices for Sustainable Manufacturing Systems". In IEEE International Conference on Automation Science and Engineering, 472-477.

SISO 2010. SISO-STD-008-2010: Core Manufacturing Simulation Data. Orlando: Simulation Interoperability Standards Organization.

Skoogh, A., and B. Johansson. 2008, December. "A Methodology for Input Data Management in Discrete Event Simulation Projects". In Proceedings of the 2008 Winter Simulation Conference, edited by S. J. Mason, R. R. Hill, L. Moench, O. Rose, T. Jefferson, and J. W. Fowler, 2664-2671. Piscataway, New Jersey: Institute of Electrical and Electronics Engineers, Inc.

U.S. Congress, Office of Technology Assessment 1993. Industrial Energy Efficiency, OTA-E-560. Washington, DC: U.S. Government Printing Office.

U.S. Department of Energy 2004. "Energy Use, Loss And Opportunities Analysis: U.S. Manufacturing and Mining".

U.S. Green Building Council 2005. "LEED: Leadership in Energy and Environmental Design". Accessed April 3, 2011. http://www.usgbc.org.

\section{AUTHOR BIOGRAPHIES}

JONATAN BERGLUND holds a Master of Automation and Mechatronics from Chalmers University of Technology. He is currently working as a guest researcher in the Life Cycle Engineering Group at the National Institute of Standards and Technology in Gaithersburg, MD, USA, while at the same time having an affiliation to Chalmers University of Technology, Division of Production Systems in Gothenburg, Sweden. Jonatan's research interest is mainly in the field of modeling sustainability aspects of production systems utilizing life cycle assessment and discrete event simulation. His email address is mailto://Jonatan.Berglund@ gmail.com.

SWEE LEONG is a senior manufacturing engineer in the Life Cycle Engineering Group at the National Institute of Standards and Technology (NIST) Manufacturing System Integration Division since 1994. Prior to joining NIST, he worked at Ford Motor Company, John Deere, and IBM on different factory automation projects. His research interests are in modeling and simulation applications for the manufacturing industries and engineering tools integration program at NIST. Currently, Swee manages the Simulation Standards Consortium at NIST. He is chairman of the CMSD Product Development Group. He received Bachelor and Master Degrees in Industrial Engineering from Purdue University in West Lafayette, Indiana. He is a senior member of the Society of Manufacturing Engineers. His email address is mailto://leong @ nist.gov.

GUODONG SHAO is a computer scientist in the Life Cycle Engineering Group at The National Institute of Standards and Technology Manufacturing Systems Integration Division. He has participated in research relating to FMS, CIMS, and manufacturing simulation integration for many years. He holds a Master's Degree from University of Maryland at College Park. He is a Ph.D. candidate at George Mason University. 
His email address is mailto://gshao@nist.gov.

FRANK RIDDICK is a computer scientist in the System Engineering Group in The National Institute of Standards and Technology (NIST) Manufacturing Systems Integration Division. He has participated in research and authored several papers relating to manufacturing simulation integration and product data modeling. He holds a Master's Degree in Mathematics from Purdue. His email address is mailto://frank.riddick@ nist.gov.

JOHN MICHALOSKI is a computer scientist in the Intelligent Systems Division at the National Institute of Standards and Technology in Gaithersburg, MD USA. His work focuses on promoting and developing machine control technology and standards. This work has lead him to chair and participate in numerous standards committees, as well as develop software and publish numerous papers related to manufacturing technology. His email address is mailto://John.Michaloski@nist.gov.

JORGE ARINEZ is currently a staff researcher in the Manufacturing Systems Research Lab at the General Motors R\&D Center. His research interests include the real-time monitoring, control, and quality of manufacturing systems with a focus on energy efficiency of plant operations. Jorge received the B.A.Sc. degree from the University of Toronto, Toronto, ON, Canada, in 1993, and the M.S. and Ph.D. degrees in mechanical engineering from the Massachusetts Institute of Technology, Cambridge, in 1995 and 2000, respectively. His email address is mailto://Jorge.arinez@gm.com.

STEPHAN BILLER received a Dipl.-Ing. degree in electrical engineering from the RWTH Aachen, Germany, a Ph.D. in Industrial Engineering and Management Science from Northwestern University and an MBA from the University of Michigan. He is a currently a Group Manager and Technical Fellow at the General Motors R\&D Center where he has responsibility for innovations in plant floor systems and controls. $\mathrm{He}$ is currently focusing on the digital factory, the real-time information enterprise, and the interoperability of the two. His email address is mailto://Stephan.Biller@gm.com 